\title{
CME
}

\section{Drive safely through the pelvis - know your pelvic roads: Paravaginal and paravesical space}

\section{K C D P Silva ${ }^{a}$, W I Gankanda ${ }^{\mathrm{b}}$, S N Samarakkody ${ }^{\mathrm{c}}$, I G D C Ilukpitiya ${ }^{\mathrm{d}}$, R D Jeewantha ${ }^{\mathrm{e}}$}

This is the third article in the series of articles unfolding avascular spaces of the pelvis. Authors recommend reading the series of articles starting from "Drive safely through the pelvis - know your pelvic roads: Retropubic space of Retzius" published in the Sri Lanka Journal of Obstetrics and Gynaecololgy ${ }^{1}$.

Figure 1 gives an overview of anatomy of the pelvic spaces.

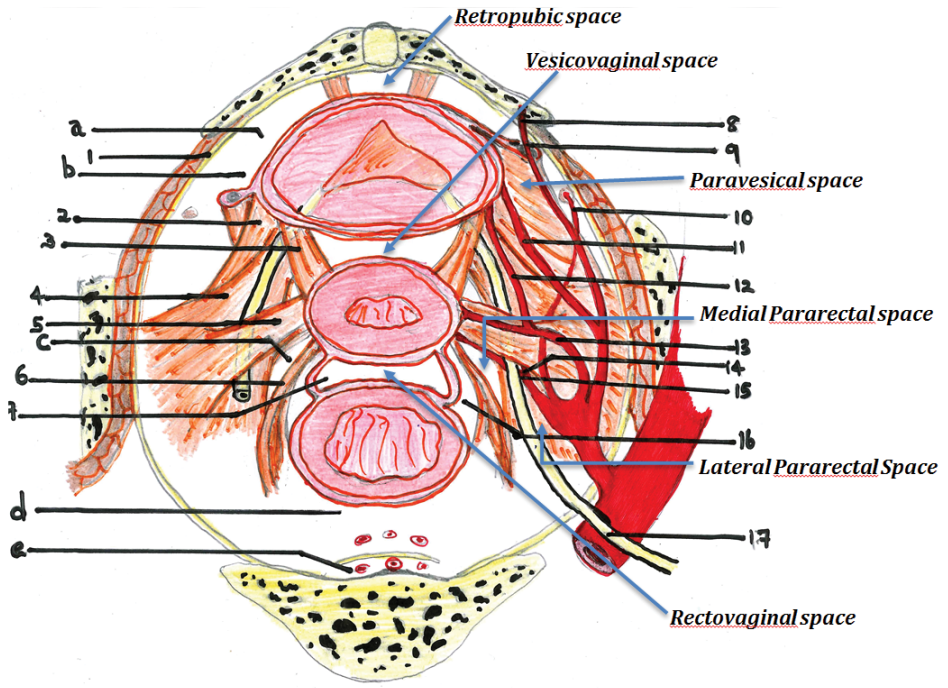

Table 1 describes the surgical procedures, which use these spaces.

Figure 2 gives a schematic representation of the paravaginal (Yabuki) space.

Figure 4 gives a schematic representation of the paravesical space.

a: retropubic space; b: Paravesical space;

c: Pararectal space; d: retrorectal space;

e: presacral space

1. Parietal pelvic fascia; 2 . Lateral vesical ligament.

3. Vesico-uterine ligament. 4. Paracervix.

5. Parametrium. 6. Uterosacral ligament.

7. Recto-uterine pouch.

8. Medial umbilical ligament.

9. Umbilicovesical fascia. 10. Obturator artery.

11. Superior vesical artery. 12. Vesicovaginal artery.

13. Uterine artery. 14. Vaginal artery.

15. Middle rectal artery. 16. Posterior vaginal fornix. 17. Ureter.

Figure 1. The schematic representation of anatomy of the pelvic spaces.

Sri Lanka Journal of Obstetrics and Gynaecology 2019; 41: 118-123

DOI: http://doi.org/10.4038/sljog.v41i4.7906

a Senior Lecturer Department of Obstetrics and Gynaecology, Faculty of Medical Sciences, University of Sri Jayewardenepura, Sri Lanka.

${ }^{\mathrm{b}}$ Senior Registrar in Department of Obstetrics and Gynaecology, Faculty of Medical Sciences, University of Sri Jayewardenepura, Sri Lanka.

c Senior Registrar in Department of Obstetrics and Gynaecology, Faculty of Medical Sciences, University of Sri Jayewardenepura, Sri Lanka.

${ }^{\mathrm{d}}$ Registrar in Department of Obstetrics and Gynaecology, Faculty of Medical Sciences, University of Sri Jayewardenepura, Sri Lanka.

e Consultant Obstetrican and Gynaecologist, Base Hospital, Mahiyanganaya, Sri Lanka.

Correspondence: KCDPS, e-mail: <dammikesilva@sjp.ac.lk>

Received $12^{\text {th }}$ October 2019 and revised version accepted $10^{\text {th }}$ November 2019.

(iD https://orcid.org/0000-0001-7438-4789

Competing interest: The authors report no conflict of interest

This is an open-access article distributed under the terms of the Creative Commons Attribution 4.0 International License, which permits unrestricted use, distribution and reproduction in any medium provided the original author and source are credited. 
Table 1. Surgical procedures carried out in each retroperitoneal pelvic space

\begin{tabular}{|c|c|c|}
\hline Retroperitoneal pelvic spaces & & Surgical procedures carried out \\
\hline \multirow[t]{4}{*}{ Medial spaces } & Retropubic & $\begin{array}{l}\text { Burch colposuspension } \\
\text { Paravaginal repair } \\
\text { Bladder mobilization in ureteric re-implantation } \\
\text { Mesh removals }\end{array}$ \\
\hline & Vesicouterine & $\begin{array}{l}\text { Mesh repair for cystocele } \\
\text { Total laparoscopic hysterectomy } \\
\text { Radical hysterectomy } \\
\text { Vesicovaginal fistula repair } \\
\text { Bladder endometriosis resection } \\
\text { Vaginal cuff resection } \\
\text { Sacrocolpopexy / Hysterocolpopexy } \\
\text { Laparoscopic abdominal cerclage } \\
\text { Scar ectopic excision }\end{array}$ \\
\hline & Recto vaginal & $\begin{array}{l}\text { Sacrocolpopexy } \\
\text { DIE of rectosigmoid } \\
\text { Vaginal endometriotic nodule dissection } \\
\text { Bowel resection }\end{array}$ \\
\hline & Retrorectal/presacral & $\begin{array}{l}\text { Bowel resection for DIE } \\
\text { Sacrocolpopexy, sacrohysteropexy, enterocele repair } \\
\text { with a mesh } \\
\text { Pre-sacral neurectomy } \\
\text { Initiation of para-aortic lymphadenectomy }\end{array}$ \\
\hline Lateral & $\begin{array}{l}\text { Paravaginal } \\
\text { Paravesical } \\
\text { Pararectal }\end{array}$ & $\begin{array}{l}\text { Pelvic lymphadenectomy } \\
\text { Radical hysterectomy } \\
\text { Excision of ureteric endometriosis } \\
\text { Ureteric reimplantation/ psoas hitch } \\
\text { Bowel resection in DIE } \\
\text { Excision of endometriosis involving sacral nerve roots }\end{array}$ \\
\hline
\end{tabular}



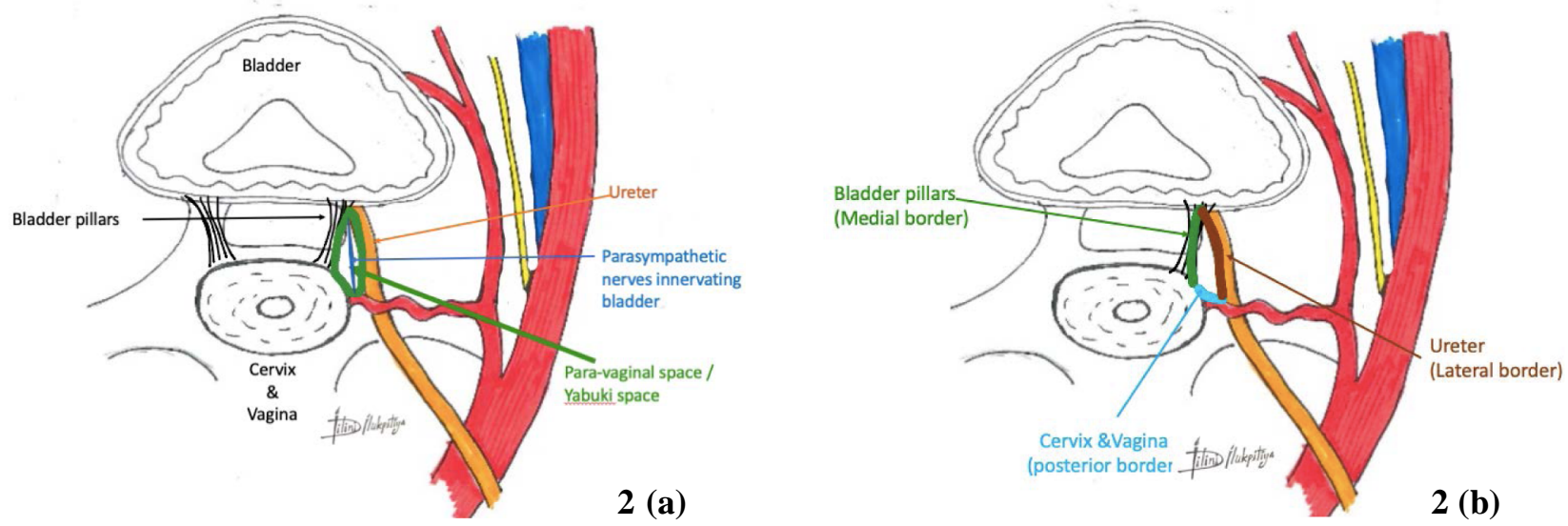

Figure 2. Paravaginal (Yabuki) space

(a) Schematic representation of the paravaginal space.

List 1 - Contents of paravaginal space.

Contents of paravaginal space.

- Parasympathetic nerves innervating the bladder

Entry in to the paravaginal space is achieved by opening the vesicouterine peritoneal fold. This space is commonly developed during radical hysterectomy which helps to avoid injury to the part of the ureter that falls in to the bladder.

"Yabuki" space is a retroperitoneal space under the uterovesical fold of peritoneum. Unlike other pelvic spaces, it is not lined by pelvic peritoneum, instead; it is lined by cervicovesical fascia. The paravaginal space is bounded by the ureter anteriorly and the anterior surface of the uterus posteriorly (Figure $2 \mathrm{a}$ and $\mathrm{b})^{2}$. The parasympathetic nerves passing along the ureter to the bladder resides in this space. The cervicovesical fascia divides into two leaves. The anterior leaf wraps around the ureter where it inserts into the bladder as well as contributing to form the superficial and deep bladder pillars, while the posterior leaf communicates (b) Boundaries of the paravaginal space. with the endopelvic fascia at the level of levator ani muscles ${ }^{3}$.

The importance of developing the paravaginal space is that, it helps to protect the distal part of the ureter lying in the lateral border of this space during dissection. This space is specially developed in nerve preserving radical hysterectomy, where the vesicouterine ligaments (bladder pillars) need to be carefully dissected off the uterine cervix to get an adequate vaginal cuff (Figure 3$)^{4}$.

Endometriosis of the distal ureter may require excision followed by reanastomosis or reimplantation. This will require dissection in to the paravaginal space to avoid any injury of the neurovascular supply of the bladder which runs in the deep vesicouterine ligaments (bladder pillars) $)^{4}$. 


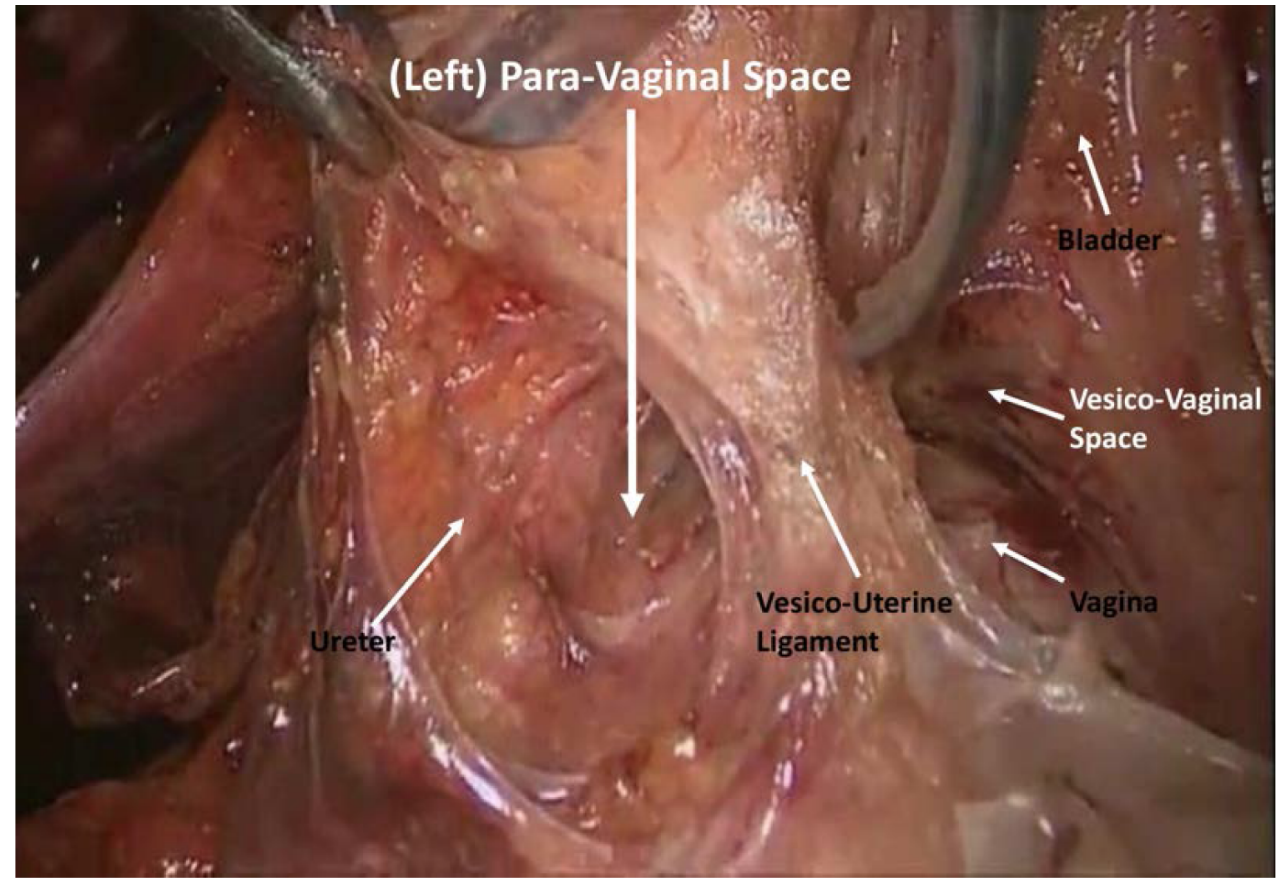

Figure 3. Laparoscopic view of the paravaginal (Yabuki) space.

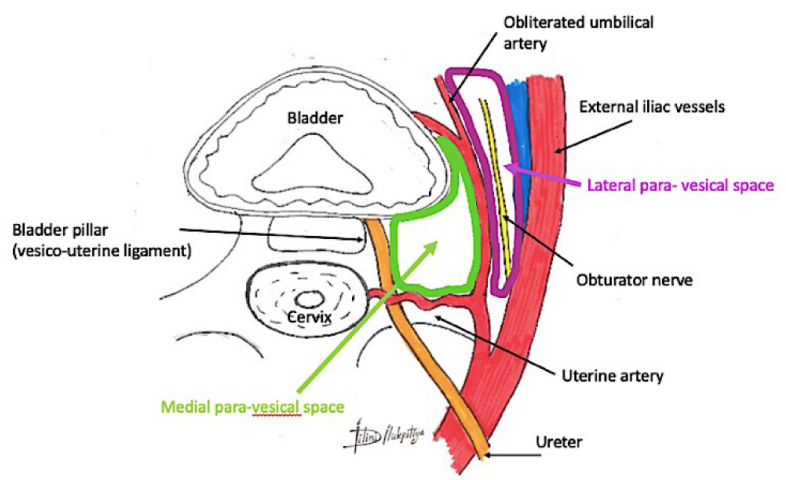

4 (a)

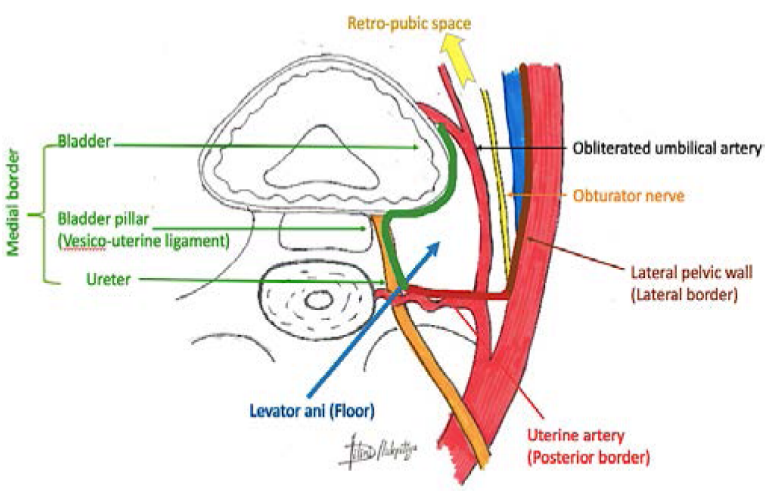

4 (b)

Figure 4. Paravesical space.

(a) Schematic representation of the paravaginal space.

(b) Boundaries of the paravaginal space.

List 2 - Contents of paravesical space.

Contents of paravaginal space.

- Obturator nerve 

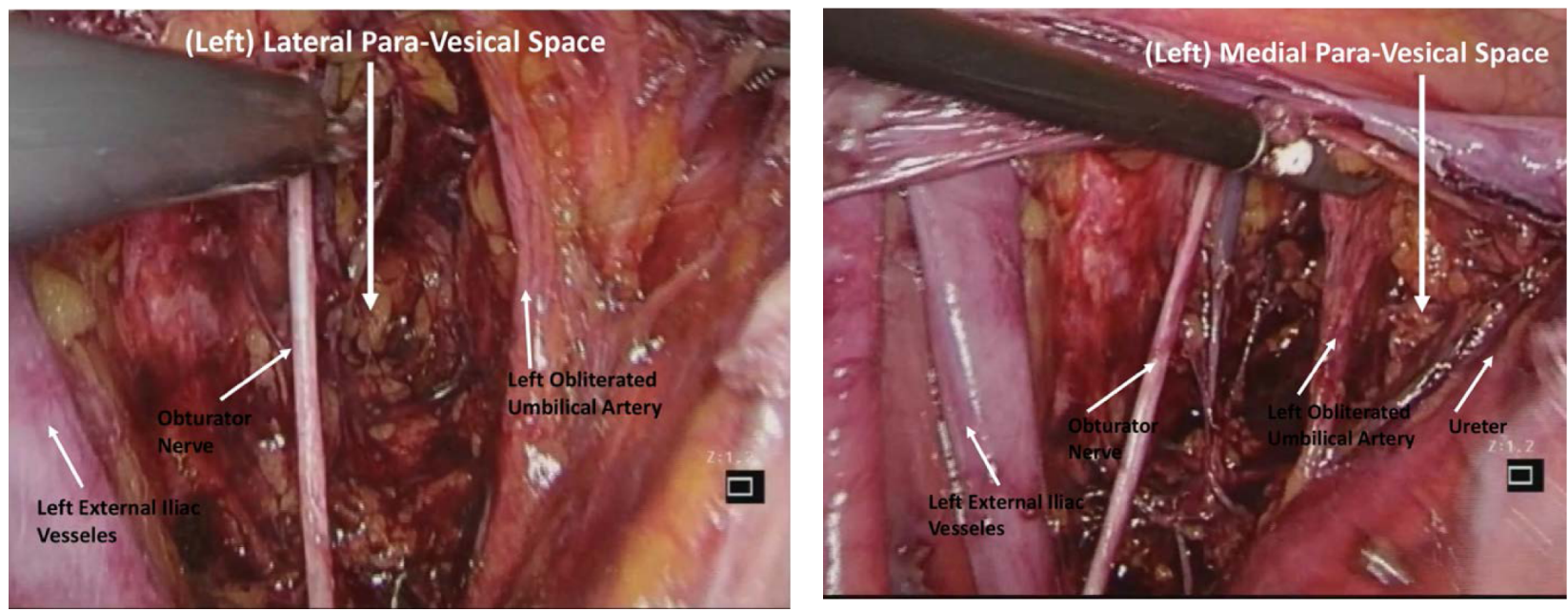

Figure 5. Laparoscopic view of the paravesical space.

The paravesical space is the retroperitoneal space that lies lateral to the urinary bladder and anterior and superior to the pararectal space ${ }^{2}$. It is bordered medially by the bladder, laterally by the pelvic walls and inferiorly by the uterine artery 3 .

Although all pelvic spaces are in continuum without specific borders from one to the other, the paravesical space can be roughly divided anatomically to lateral and medial subspaces by the obliterated umbilical ligament.

The pararectal and paravesical spaces communicate with each other as well as with the retropubic space.

Initial entry in to the paravesical space can be done in two ways. Either by division of the round ligament or by dissecting parallel and in front of the infundibulopelvic ligament; delicate and cautious dissection is extremely important as this space contains major blood vessels and nerves ${ }^{4}$.

The obliterated umbilical artery is a very useful anatomical landmark for the pelvic surgeon. This arbitrarily divides the paravesical space in to medial and lateral subspaces. The medial paravesical space is the only space where vessels cross from the lateral to medial side (uterine artery and veins), Therefore, dissecting parallel along the space can damage these vessels. All other lateral spaces have the essential structures travelling parallel to the space and therefore parallel dissection is generally safe.
The major use of the lateral paravesical space is for pelvic lymphadenectomy as this space contains the external iliac and obturator lymph nodes. Extreme care must be taken while clearing lymph nodes around the external iliac artery, vein and the psoas muscle as well as from around and below the obturator nerve ${ }^{2}$. There is a wide anatomical variation of the obturator artery and vein below the obturator nerve which requires very delicate dissection. The obturator nerve originates from the ventral rami of second, third and fourth lumbar nerves. It provides sensory perception to the skin on the medial side of the thigh and motor function to the hip joint, knee joint, adductor muscles and gracilis muscle. Injury to obturator nerve results in weakness of adduction, external rotation of the thigh as well as the loss of sensory perception to the skin of the medial side of the thigh. Care must be taken not to harm the genitofemoral nerve running along the psoas muscle. The lower limit of dissection for the lateral paravesical space is marked by the pelvic floor ${ }^{2}$.

The medial paravesical space is dissected during radical hysterectomy to clip the uterine artery at its origin from the internal iliac artery. Clipping the uterine artery is also used to minimize blood loss during difficult hysterectomy and myomectomy. Just underneath the origin of the uterine artery is the superficial uterine vein and deeper to that is the deep uterine vein. The limit of dissection for the medial paravesical space is marked by the floor formed by levator ani muscles ${ }^{3}$. 


\section{Conclusion}

Both spaces are made use of in many gynaecological surgeries. Thorough knowledge of these spaces and its contents is essential for the pelvic surgeon to achieve surgical excellence while minimizing morbidity. Surgery in these spaces should be guided by meticulous anatomical knowledge.

Articles describing the other pelvic spaces will follow in future issues.

\section{References}

1. Silva KCDP, Samarakkody SN. Drive safely through the pelvis - know your pelvic roads
Retropubic space of Retzius. Sri Lanka J Obstet Gynaecol. 2019 Jul 18; 41(2): 55.

2. Puntambekar S, Manchanda R. Surgical pelvic anatomy in gynecologic oncology. Int J Gynaecol Obstet [Internet]. 2018 Oct [cited 2019 Sep 1];143 Suppl:86-92. Available from: http:// www.ncbi.nlm.nih.gov/pubmed/30306582

3. Rabischong B. Laparoscopic anatomy of the female pelvis, from the peritoneum to the retroperitoneum.

4. A Practical Manual of Laparoscopy and Minimally Invasive Gynecology. A Practical Manual of Laparoscopy and Minimally Invasive Gynecology. CRC Press; 2007. 